\title{
A Case Study on School Innovation and Change
}

\author{
Aneta Walker, Ph. D. \\ University of West Florida \\ 11000 University Parkway Pensacola, Florida
}

\begin{abstract}
The implementation of the rigorous, complex Common Core State Standards (CCSS) has prompted schools to initiate change in traditional organizational structures. The CCSS have required teachers to have a deeper understanding of subject matter and specialized content instruction to effectively teach the standards. There is a vast amount of research on educational change as related to school improvement, however, this research analyzed how schools create a context for change to implement a new innovation and improve the learning environment. The purpose of this research study was to evaluate the effectiveness of an innovative hybrid schedule in improving student learning outcomes and school culture. This mixed-method research study used data generated by the Stages of Concern Questionnaire (SoCQ), AdvancEd®’s Stakeholder Feedback Survey, ACT Aspire ${ }^{\circledR}$ Student Achievement Tests, and teacher interviews. The conceptual framework of the case study was based on the five attributes of the PLCs identified through the work of Shirley M. Hord (2004) and Michael Fullan's Educational Change Theory (2007). The results of this study indicated the implemented innovation had a significant impact on school culture based on the two administrations of the AdvancEd®’s Stakeholder Feedback Survey. Additionally, student learning outcomes measured by ACT Aspire® Reading and Mathematics Student Achievement Tests showed statistically significant improvements in both reading and math. Lastly, the analysis of teacher interviews supported the findings in the quantitative data.
\end{abstract}

Keywords: innovation, educational change, student learning outcome, school culture

\section{INTRODUCTION}

In the midst of ever changing curriculum, higher expectations, and increasing accountability, those leading schools have immense responsibilities and challenges in the implementation of change initiatives. An essential factor in any school reform initiative has been to understand school culture, as examined by Hinde (2004) in the article, School Culture and Change: An Examination of the Effects of School Culture on the Process of Change. Hinde (2004) quantified "any change introduced to schools is often met with resistance and is doomed to failure as a result of the reform being counter to this nebulous, yet all-encompassing facet-school culture" (p. 4). In a National Association of Elementary School Principal's article that appeared in Principal Magazine, stated "that the school's culture is key to professional growth and learning, and established through building trust" (Danielson, 2012, p. 26). Sergiovanni (1992), suggested that true leadership emanates from the 
heart of the leader where decisions, actions, and relationships are made from moral connections grounded in the cultural norms of a school. These core concepts provide the foundation of establishing a positive school community.

Research supports the idea that there was a significant connection between school culture and successful school change (Fullan, 2007; Stoll, 2009) . Fullan (2007) stated that collaboration played a critical role in the school change process. He believed that school culture was based on the belief systems and expectations that are evidenced by the way a school operates. The school's culture was established over time by trying to make sense about situations and experiences. For example, every school has a set of expectations about specific topics that are discussed at meetings, best practices and methods, the willingness of teachers to change, and the level of importance and role of professional development (Bolman \& Deal, 2010; Deal \& Peterson, 1999; Fullan, 2007).

According to Sowers (1968), meeting the varying needs of students was the first priority for every school. Yearly issues that must be addressed by elementary principals are student achievement and how to organize the school for instruction (Williams, 2009). To address these issues, school principals must identify and establish changes in the organizational structure of traditional elementary school models which support increasing content knowledge and skills of teachers. In order to provide high quality instruction, educational programs, and practices require constant evaluation to identify areas of improvement and needed change.

Schools are challenged to be innovative to inspire and drive change for improving student learning outcomes and the instructional process. Effective educational practices for implementing innovation and change are aligned with the framework of this study. To create consistent and sustained change, research has shown that the organization as a whole must initiate, implement, and maintain accountability for change to become solidified practice. Supportive conditions must be created also for individual teachers to experiment and try new ideas in order for the change to flourish and for organizational learning to occur. According to Fullan (2007), "Real change, whether desired or not, represents a serious personal and collective experience characterized by ambivalence and uncertainty; and if the change works out, it can result in a sense of mastery, accomplishment, and professional growth" (p.23). For innovation to be sustained within an organization, support must be provided to those responsible for the implementation of change. Innovation cannot stand alone.

\section{Purpose of the Study}

Departmentalization is not a new concept in education. Middle schools and high schools have utilized a departmentalized organizational structure for years. However, applying the idea to elementary school seems to be a break from tradition, a long held belief that an elementary school should have a one teacher per classroom model. Departmentalization at an elementary school is controversial because many believe it does not lend to teaching the whole child (Becker, 1987; Chang et al., 2008; Dropsey, 2004; Harris, 1996). This traditional school of thought is held because some believe that younger students benefit from the relationships established because the students are with the same teacher, same students all day every day for the entire school year. However, elementary school teachers are trained to be generalists that teach all of the core subjects of math, reading, science, social studies, and language arts (Chan \& Jarman, 2004; Chang et al., 2008; Contreras, 2009; Delviscio \& Muffs, 2007; Dropsey, 2004; Hampton, 2007; Hood, 2009; McGrath \& 
Walker, A. (2020). A Case Study on School Innovation and Change. Advances in Social Sciences Research Journal, 7(4) 148-163.

Rust, 2002; McPartland, 1987). However, some elementary schools have adopted a hybrid schedule to allow teachers to maintain their student relationships, while still engaging in some departmentalization.

The hybrid schedule is a variation of departmentalization coupled with ability grouping. This innovative approach allows teachers to become specialists in one content area and individualize instruction through use of small group leveled instruction. Additionally, the formulation of the hybrid schedule offers opportunities for teachers to discuss specialized content and participate in a learning community focused on improving their instructional practice. Teachers plan and collaborate vertically with other subject specific teachers as well as work collectively within their grade levels. This study focused on investigating the degree to which the implementation of this type innovation impacts school culture and student learning outcomes.

\section{Problem Statement}

Educational reform appears to be a movement that is being pursued by politicians and educational leaders across the country. The implementation of the Common Core State Standards has required schools to change the structure and content of their curriculum because the new standards are more rigorous and in-depth than previous state standards (CCSSI, 2012; Porter, McMaken, Hwang, \& Yang, 2011). Traditional elementary school organizational structures and how they function is a growing concern relative to the newly adopted standards. One reason is the fact that the Common Core State Standards define the skills and knowledge essential for students to succeed in college and the workplace (NEA, 2010). The standards represent an increase in the difficulty and complexity in the math and English language arts (CCSSI, 2012; Porter et al., 2011). Schools must be prepared and organized for the changes required to teach these standards effectively.

In order to address the reality of the concerns and promote change for the better, the individuals responsible for improving the instruction and curriculum are required to change their behavior (DuFour, Eaker, \& DuFour, 2005). Fullan (2003) stated that "it is only by raising our consciousness and insights about the totality of educational change that we can do something about it" (p. vii). In order for success to occur, teachers need to be placed in a structured environment that allows them to focus on the connections between their organization and management skills and how they facilitate their learning and their students' learning (Fullan, 2003; 2007). Zmuda, Kuklis, and Kline (2004) stressed that the school should be an effective organization that requires a significant change from "unconnected thinking to systems thinking, from perceived reality to informationdriven reality, and from individual autonomy to collective autonomy and collective accountability" (p. 1). DuFour et al. (2004) stated that there are two categories for schools, those that succeed and those that do not. For organizations to lead successful change, schools should create a learning community (Fullan, 2007). Consequently, this type of learning community requires organizational change (Fullan, 2003, 2007).

Change often encompasses the implementation of an innovation such as an idea, new knowledge, or a physical object, such as an innovative hybrid schedule. Educators are often left out of the conversations centered around change initiatives and as a result there is not a clear understanding of how change is affecting them. Fullan (2007) posits that one of the main reasons that change fails is that there is not underlying conception that grounds what would happen with new structures. Additionally, Fullan (1993) stated that educators must, "redesign the workplace so that innovation 
and improvements are built into the daily activities of teachers... and adopt institutional renewal with new forms of leadership, collegiality, commitment to, and mechanisms for continuous improvement" (p. 353). In order to accomplish such organizational agility, schools will need to empower teachers and administrators to develop solutions collaboratively (Weller \& Weller, 1997). Consequently, if schools are to evolve, to truly become a vehicle for continuous improvement and learning, then they must develop a culture capable of continuous change (Fullan, 1993; 2004; 2007). The question that remains is whether or not an innovation spawned from the need for changing a cultural context within a school can be sustained through a framework of a learning community which fosters a collaborative, synergistic capacity for continuous improvement. Therefore, how do schools that are striving to be innovative leverage new ideas or unproven methods to improve practice or solve persistent problems implement change to effectively improve school culture and student learning outcomes?

\section{Background of the Hybrid Schedule at Stella Elementary School}

Schools are complicated organizations, both socially and politically. Every school has differing levels of interacting cultures, cultural influences, structural designs, values, beliefs, bureaucratic and political influences, and highly complex operating environments. This holds true at Stella Elementary School. Stella is a kindergarten through fifth grade elementary school, one of eleven elementary schools in the Eagle City Schools' System. The school serves approximately 410 students. The student population served is primarily from low socio-economic households. Ninetysix percent of the students received free and reduced lunches. Due to the high number of students living at or below poverty status, Stella also received schoolwide Title I funding. In addition to high poverty, Stella's student population is highly transient.

Stella's organizational purpose and educational goal is centered on student growth. In order for students to be successful, as well as be college and career ready, Stella's staff is charged with the establishment of a strong educational foundation for students by emphasizing analytical skills, a deeper understanding of concepts, and applied knowledge rather than simple recall of facts. For many years the school system's curriculum has been a mile-wide and an inch-deep approach to subject matter. However, changes in the curriculum with the Common Core State Standards (CCSS) has required a deeper level of knowledge, critical thinking, and application of skills for both teachers and students. Ultimately, every student needs to think critically and analytically to successfully master the new CCSS for Math and English Language Arts. Thus, implementing the CCSS required changes in the instructional and planning processes. These components are essential and critical to continuous improvement an improving student learning outcomes.

Eagle City Schools are required to adhere to the AdvancED® continuous school improvement standards for accreditation. Under AdvancED® guidelines, schools are required to review school improvement standards and provided documentation of adherence to the five Quality School Standards: (1) Purpose and Direction, (2) Governance and Leadership, (3) Teaching and Assessing for Learning, (4) Resources, and (5) Support Systems. Embedded throughout the Quality School Standards are the common themes of continuous improvement, stakeholder involvement, student engagement, collaboration, equity, and personalization. Additionally, included within each standard is a strong focus on teaching and learning. Furthermore, the standards address how the school prepares students with skills needed for the future and analyzed the schools' high expectation for professional practice. 
At Stella, the term continuous improvement is defined as constant review and evaluation of every factor that affects teaching and learning. In order to evaluate, a comprehensive needs assessment is conducted that analyzes programs, methods, instructional strategies, organizational structure, and culture indicators within the school. At the end of the 2015-2016 school year, Stella's Building Leadership Team (BLT) intensely analyzed the AdvancED® Stakeholder Feedback Diagnostic that reported and determined that the school's morale, climate, and culture was in need of improvement. Further analysis revealed that teachers' believed they were not meeting the needs of the various levels of students due to the fact that they had multiple subject areas and student ability levels for which to plan. Additionally, the implementation process for initiatives such as CCSS and RTI was making planning alarmingly difficult to nearly impossible. It was determined that the school morale and climate was stifled by the number of new curricular expectations and documentation requirements.

Each member of the Building Leadership Team was charged with identifying possible root causes of the low morale issue. This team then collected feedback from the faculty. As a whole, the entire faculty was distraught over the insurmountable workload they were contending with on a daily basis. At this point every teacher was responsible for the following:

1. Planning for whole group and small group reading and math instruction

2. Differentiating instruction for intervention for math and reading, science, social studies, and writing,

3. Planning Center activities,

4. Progress monitoring reading fluency,

5. Scoring writing prompts according the Eagle City Schools Writing rubrics each nine weeks,

6. Monitoring and assigning student activities in benchmark tests,

7. Providing documentation for Response to Instruction for students on Tier II and Tier III intervention,

8. Grading and re-assessing students for reading and math,

9. Infusing the technology standards in the curriculum, and

10. Preparing for the implementation of the Alabama College and Career Standards.

The key cause indicated was teachers were struggling with the implementation of current shifts in instruction for the CCSS for Math and English Language Arts. As a team, the staff unanimously determined that radical changes needed to be made to the organizational structure which would allow teachers to teach one core content area. The recommendation to investigate a hybrid model or version of departmentalization grades 1 through 5 was approved by the Building Leadership Team (BLT), and teams of teachers moved forward with researching and investigating options.

Opportunities were provided for teams of teachers to observe at schools that were departmentalized or had implemented a modified departmentalized schedule. The BLT was able to question the teachers about their perceptions and concerns about departmentalizing. Additionally, the teachers were able to ask if they supported and believed that student learning outcomes had increased by focusing on planning for one content area. Other questions asked centered around the possibility of increased additional opportunities for teachers to engage students in rigorous activities, as well as if they had additional time to differentiate instruction. Finally, they addressed ability grouping and if they believed it added positive curriculum experiences for students through ability grouping. Many teachers asked if the teachers saw departmentalizing as an improvement 
that allowed for targeted professional development for the subject area they were responsible for teaching.

At the end of the school year, the faculty decided that a hybrid model of a departmentalized schedule was a viable option. In this variation of a departmentalized organizational structure, teachers were only required to plan and master one subject area of the CCSS. Teachers felt they could become a master teacher in one subject area and could plan more effectively for one content area. The system administration approved the hybrid schedule for Stella. A committee was established to develop a schedule based on selected research and observation data that had been collected from the school visits. Using the scheduling and observational data gathered, Stella Elementary School implemented the new schedule at the beginning of the new school year.

Over the course of the first semester, revisions were made as needs or concerns were identified. Student learning outcomes data, perceptional and process data, as well as school climate and culture indicators still need to be collected to determine whether the innovative hybrid schedule had a positive impact on student learning outcomes, instructional practices, and school culture.

All teachers at Stella had input in the planning, organization, and implementation of the new hybrid schedule and organizational structure. Stella implemented this new innovative hybrid schedule that reflected the ideas and proposals provided by the entire staff. The hybrid schedule was structured for whole group instruction in the morning for Reading, Math, and Literacy Standards for Science and Social Studies. The afternoon schedule was organized into leveled small groups in order for teachers to target the needs of the various levels of student performance. With this model, higher performing students were given challenging instruction. The lower performing students were provided with individualized and differentiated instruction. Instructional aides, tutorial staff, and special education staff members were assigned to assist with the lower performing small groups in order to support the teachers and help students within those groups. The implementation of the innovative hybrid schedule encouraged teachers to work collaboratively and focus on planning for and implementing engaging lessons for their subject area. It was evident that a shift within the school's culture was triggered as teachers worked and planned together.

\section{CONCEPTUAL FRAMEWORK}

A central focus of scholarly research on educational change has indicated that change is a complex process. There is ample research evidence that building the capacity of organizations to learn through professional learning communities can be powerful in establishing collegial trust, organizational change, continuous improvement, and ultimately improving student learning outcomes (Fullan, 2007; Fullan \& Hord, 2015; Hall \& Hord, 2004, 2011). The forces require a new educational paradigm that shifts from traditional systems to a mindset of collaboration. In turn, this mindset will foster a continuous capacity for change. Schools that adopt collaborative learning environments create a cultural context that is conducive for continual improvement. There is evidence to suggest that a school's capacity for change is directly related to its culture and overall organizational structure (Fullan, 2007; Fullan \& Hord, 2015; Hall \& Hord, 2011; Hargreaves, 1997; Miller, 2002).

A study's conceptual framework provides an outline for discussing the theoretical underpinnings. According to Miles and Huberman (1994), "A conceptual framework explains either graphically or 
in narrative forms the main ideas to be studied-the key factors, constructs, or variables-and the presumed relationship among them" (p. 6). The conceptual framework of the present case study was based research conducted on the five attributes of the PLCs identified through the work of Shirley M. Hord (2004) and Michael Fullan's Educational Change Theory (2007). Hord's five attributes were: 1) Shared Values and Vision, 2) Intentional Collective Learning, 3) Supportive and Shared Leadership, 4) Supportive Conditions, and 5) Shared Personal Practice. Fullan's educational change theory has three phases: Phase I - Initiation; Phase II - Implementation; and Phase III Institutionalization.

\section{Professional Learning Community Attributes}

Shirley Hord's (2004) five attributes for PLCs are:

1. Supportive and Shared Leadership - The act of teams of teachers and administrators collaborate and work together to focus on improving student learning outcomes and school improvement results. Fullan (2000) stressed that decision-making and problem-solving is shared by all stakeholders. The power is a shared process and all have a shared ownership in the process.

2. Shared Values and Beliefs - Student learning and the success of all students was the focus of all PLC members. Each member identifies with the schools' vision, purpose, and core values. Members understand his or her role and purpose in achieving the schools' goals that were aligned to the vision and mission of the stakeholders in the school. The staff worked together to improve instructional practices. In doing so, the vision, and all it involves continued to improve as the staff strives to achieve success for all students. Peterson (1995) expressed the following idea about having a shared vision:

3. Many schools do not have a clear and shared sense of purpose focused on student learning. Yet, without it, programs become fragmented, teachers lose motivation, and improvement efforts fail... Without a clear sense of direction, planning and decision-making about programs, curricula, and instruction can remain uncoordinated. (p. 1)

4. Collective Group Learning - Collective group learning reflects the efforts focused on building the learning capacity of the members. All members of the learning organization are engaged in structured and deliberate collaboration focused on improving student learning. The process is student learning-centered and it is a continuous action-oriented cycle.

5. Supportive Conditions - Important and necessary component for leadership to plan for opportunities for members to meet. This condition is logistics. Structured time, place, and action items needing attention are addressed and discussed within the school day. The second condition necessary is a space for relationships to develop and build trust and confidence among participants.

6. Shared Personal Practice - Teachers working together to improve instruction. This dimension of shared personal practice is often the last to develop. The challenge is bringing teachers out of isolation. Teachers working together collaboratively in teaching and learning environment is a learned skill that requires some training. This requires teachers to visit classrooms and observe teaching and learning, taking notes, and giving feedback to their peers. The purpose of this attribute is individual and organizational learning and improvement. 
Fullan (2007) explained the complexity of educational change as:

Thus, on the one hand, we need to keep in mind the values and goals and the consequences associated with specific educational changes; and on the other hand, we need to comprehend the dynamic of educational change as a sociopolitical process involving all kinds of individual, classroom, school, local, regional, and national factors at work in interactive ways. (p. 9)

\section{Fullan's Change Theory}

This is the basis of the second component of this study's conceptual framework based on the three phases that comprise Fullan's (2007) educational change theory. Within the first phase, initiation, a change is adopted or initiated. Phase I occurred when a need was realized by individuals or groups within an organization. Phase II, the implementation phase, involved the change process after an adopted change occurred. Phase III, institutionalization, referred to the sustainability of the innovation within the organization.

The alignment of this study's conceptual framework are encompassed in AdvancED ${ }^{\circ}$ (2014) research. This research on continuous improvement cycle solidified that continuous change and improvement process for schools must adhere to and address the five Quality Schools Standards. The standards for Quality Schools are:

- Standard 1: Purpose and Direction

- Standard 2: Governance and Leadership

- Standard 3: Teaching and Assessing for Learning

- Standard 4: Resources and Support Systems

- Standard 5: Using Results for Continuous Improvement.

These standards align with the characteristics of Hord's five attributes of PLCs and are accomplished through Fullan's (2007) phases of educational change. Figure I is a visual representation of the three frameworks of the study. 


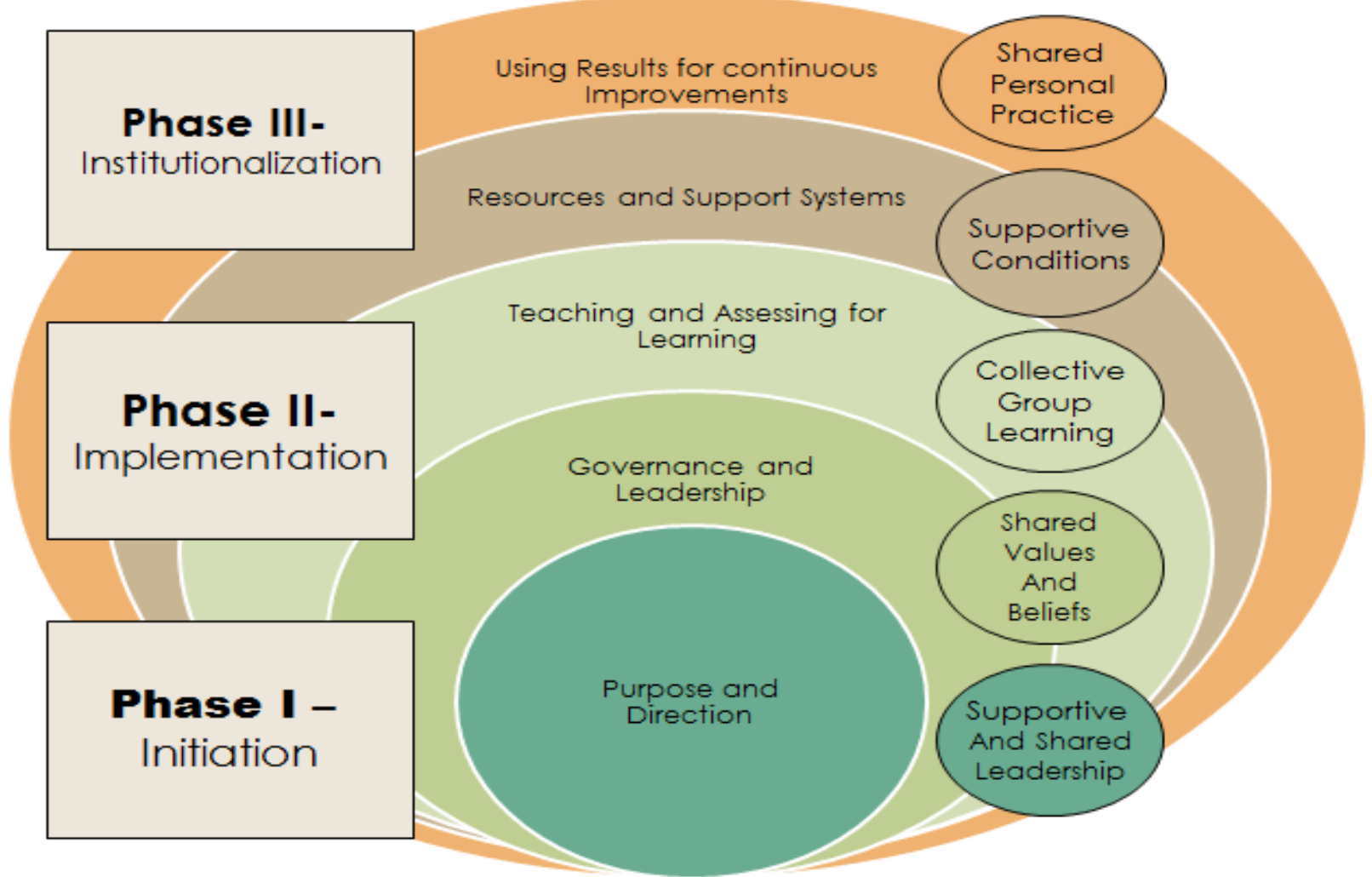

Figure 1. Conceptual Framework Correlated with Quality School Standards

\section{Research Questions}

The research questions that guided this study were:

1. What do teachers perceive as factors that facilitated and/or hindered the implementation of the Innovative Hybrid Schedule?

2. As perceived by the teachers, to what extent has the school culture changed as a result of the implementation of the Innovative Hybrid Schedule?

3. To what extent have student learning outcomes changed with the implementation of the Innovative Hybrid Schedule?

4. What are the perceived program outcomes related to the implementation of the Innovative Hybrid Schedule?

\section{RESEARCH METHODS}

This mixed methods case study utilized various data collection instruments. The combination of quantitative and qualitative data collection made mixed methods a strong design to utilize (Creswell, 2015). Table 1 shows the specific data collection instrument used to answer each of the research questions. The use of multiple quantitative and qualitative instruments provided the researcher the data sources to demonstrate triangulation of data and strengthen the inquiry (Creswell, 2012, 2015). 
Table I: Data Collection Instruments and Research Questions

\begin{tabular}{ll|l}
\hline \hline \multicolumn{1}{c|}{ Research Question } & \multicolumn{1}{c}{ Data Collection Instruments } \\
\hline $\begin{array}{l}\text { 1. } \begin{array}{l}\text { What do teachers perceive as factors that facilitated } \\
\text { Innovative Hybrid Schedule? }\end{array} \\
\text { 2. } \begin{array}{l}\text { As perceived by the teachers, to what extent has the } \\
\text { school culture changed as a result of the } \\
\text { implementation of the Innovative Hybrid Schedule? }\end{array}\end{array}$ & $\begin{array}{l}\text { AdvancED's@ stakeholder feedback diagnostic survey } \\
\text { Interviews }\end{array}$ \\
\hline $\begin{array}{l}\text { 1. } \\
\text { Have student learning outcomes changed with the } \\
\text { implementation of the innovative hybrid schedule? }\end{array}$ & $\begin{array}{l}\text { ACT Aspire® Test Scores } \\
\text { What are the perceived program outcomes related to } \\
\text { the implementation of the Innovative Hybrid } \\
\text { Schedule? }\end{array}$ & \\
\hline
\end{tabular}

This case study investigated the effectiveness of implementing an innovation to bring about a change in school culture and student learning outcomes. The researcher attempted to deepen the understanding of the relationships among educational change, school culture, student learning outcomes and continuous improvement.

The participants included teachers who had been a part of the implementation of the innovative hybrid schedule. The participants were active members of the established professional learning community. Multiple data sources were collected including questionnaires, surveys, interviews, documents and artifacts, observations, and student learning outcomes data.

This research study employed a mixed method case study utilizing a convergent design. The school, which was the subject of the study, had implemented an innovative hybrid schedule over a two-year period. In addition, the selected school site implemented the different components of professional learning communities in an effort to strengthen collaboration and improve school culture. Purposeful sampling was used for this study.

The purpose of the mixed method case study was trifold. First, research was conducted to examine the implementation of an innovation and whether the school culture changed as a result of the innovation. Second, research was conducted to determine the level of teachers' concerns about implementing the innovative hybrid schedule. Third, the study was conducted to determine if instructional practices improved and if student learning outcomes improved. Furthermore, a case study provided descriptions of how a school culture functioned from those participants that were actively involved. This approach served my research paradigm and conceptual framework for understanding the relationships how implementing an innovation effected school culture and drove the process for continuous improvement by utilizing the attributes of professional learning communities. Being able to gain a comprehensive and holistic view of the case within a bounded system provided for a deeper understanding of how change happened. Additionally, it included the context as well as details related to the case being studied.

The qualitative data used in this case study were collected through in-depth interviews. The quantitative data were collected over a two-year period. The survey data were collected at the beginning and end of each school year. The survey used was $A d v a n c E D$ 's ${ }^{\circledR}$ stakeholder feedback 
diagnostic tool that was used to measure the school climate. The surveys were administered to address the Standards for Quality Schools and was electronically formatted through the AdvancED® Assist portal. Additional quantitative data were gathered through the questionnaire used based on the Stages of Concern Questionnaire (SoCQ). The SoCQ was administered in a pencil-paper format. The student learning outcome data were generated using ACT Aspireß. These data were state mandated and administered to all third through fifth graders.

\section{RESULTS}

Results of the data analysis revealed a statistically significant correlation between the innovative hybrid schedule and improvement in student learning outcomes based on the ACT Aspire® test scores. Statistically significant gains were shown in Table II and Table III for both data sets of $3^{\text {rd }}$ to $4^{\text {th }}$ grade reading and math and $4^{\text {th }}$ to $5^{\text {th }}$ reading and math scores.

Table II Means, Standard Deviations, Degrees of Freedom, Eta Square, and p Values for the ACT Aspire ${ }^{\circledR}$ Mathematics Test

\begin{tabular}{|c|c|c|c|c|c|c|c|}
\hline \multirow{3}{*}{ 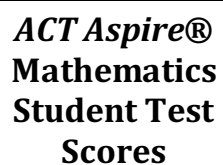 } & \multicolumn{2}{|c|}{ Spring 2015} & \multicolumn{2}{|c|}{ Spring 2016} & \multirow[b]{2}{*}{$F$} & \multirow[b]{2}{*}{ Eta Square } & \multirow[b]{2}{*}{$\mathrm{p}$} \\
\hline & Mean & SD & Mean & SD & & & \\
\hline & 412.19 & 3.541 & 414.49 & 3.118 & 35.517 & .346 & $<.001$ \\
\hline
\end{tabular}

Table III Means, Standard Deviations, Eta Square, and p Values for the ACT Aspire® Reading Test

\begin{tabular}{c|cc|cccccc}
\hline \multirow{2}{*}{$\begin{array}{c}\text { ACT Aspire }{ }^{8} \\
\text { Reading Student } \\
\text { Test Scores }\end{array}$} & \multicolumn{2}{|c|}{ Spring 2015 } & \multicolumn{2}{|c}{ Spring 2016 } & & & \\
\cline { 2 - 8 } & Mean & SD & Mean & SD & F & Eta Square & $p$ \\
\cline { 2 - 8 } & 411.26 & 4.544 & 414.04 & .4 .542 & 45.946 & .407 & $<.001$ \\
\hline
\end{tabular}

On the overall ACT Aspire $®$ Mathematics test data, Stella Elementary School tested n $=69$ students in grades one through five. The mathematics data points included ACT Aspire® Spring 2015 Mathematics and 2016 Spring Mathematics for $3^{\text {rd }}-4^{\text {th }}$ grade and $4^{\text {th }}-5^{\text {th }}$ grade students. The data indicated statistical significance was reached in both groups.

Stella Elementary School tested $\mathrm{n}=69,3^{\text {rd }}-4^{\text {th }}$ and $4^{\text {th }}-5^{\text {th }}$ grade students on the ACT Aspire® Reading (. The 2015 Spring administration of the ACT Aspire ${ }^{\circledR}$ were the baseline scores. Only the students that completed both testing sessions at Stella Elementary School were used in the data sets. The data revealed that statistical significance was reached in the ACT Aspire ${ }^{\circledR}$ Reading test scores. The tables provided the descriptive statistics for ACT Aspire® Reading test data. The data indicated statistical significance was reached. There was a large effect size eta $=.407$ indicated a strong relationship between the implementation of the Innovative Hybrid Schedule.

Based upon the statistical analysis, each data set showed statistical significance. The overall data for data for mathematics and reading showed that statistical significance was reached after the implementation of the innovative hybrid schedule.

Additionally, statistically significant gains were shown in the AdvancEd@'s Stakeholder Feedback Survey results with each of the following Quality School Standards: Purpose and Direction Governance and Leadership, Teaching and Assessing for Learning, Resources and Support Systems, 
and Using Results for Continuous Improvement. Means, standard deviations and results of the Spring 2015 and Spring 2016 administration of the AdvancEd®'s Stakeholders Feedback Survey were reported for each of the five standards addressed in the AdvancEd®'s Stakeholder Feedback Survey.

These were reported as Purpose and Direction, Governance and Leadership, Teaching and Assessing for Learning, Resources and Support Systems, and Using Results for Continuous Improvement. The correlations, Eta Square between the Spring 2015 and Spring 2016 of the AdvancEd@'s Stakeholder Feedback Survey ranged from .382 to .183. This was interpreted as a large effect size. In order to assess whether or not school culture and climate changed during the implementation of the innovative hybrid schedule the researcher completed a two level within subjects Analysis of Variance (ANOVA). In Table IV, the five standards' average resulted in a statistically significant change, $F(1,4)=29.718, p<.001$ with the mean scores for the Spring 2015 lower than Spring 2016 for all five sections identifying school culture and climate indicators.

Table IV Means, Standard Deviations, Eta Square, and p values for Purpose and Direction, Governance and Leadership, Teaching and Assessing for Learning, Resources and Support Systems, and Using Results for Continuous Improvement addressed by AdvancEd®’s Stakeholder Feedback Survey

\begin{tabular}{|c|c|c|c|c|c|c|c|}
\hline \multirow{3}{*}{$\begin{array}{c}\text { AdvancEd®'s } \\
\text { Stakeholder } \\
\text { Feedback } \\
\text { Survey }\end{array}$} & \multicolumn{2}{|c|}{ Spring 2015} & \multicolumn{2}{|c|}{ Spring 2016} & \multirow[b]{2}{*}{$\mathrm{F}$} & \multirow[b]{2}{*}{ Eta Square } & \multirow[b]{2}{*}{$\mathrm{p}$} \\
\hline & Mean & SD & Mean & SD & & & \\
\hline & 4.1417 & .14384 & 4.2872 & .15171 & 29.718 & .382 & $<.001$ \\
\hline
\end{tabular}

In interpreting the $A d v a n c E d 囚$ 's Stakeholder Feedback Survey, the innovative hybrid schedule promoted a positive school culture. Additionally, the effect size was large, partial eta ${ }^{2}=.382$. This could indicate the possibility that the school culture was significantly improving in a positive direction and the school culture was perceived by teachers in a positive manner after the implementation of the Innovative Hybrid Schedule.

Teacher interviews supported the findings from the quantitative data. Three consistent themes emerged from the interviews to validate the quantitative data. They were as follows: Teacher Collaboration, Improvement in School Culture, and Teachers as Content Specialist.

\section{School culture.}

The process of data triangulation revealed the emergent theme of improvement in school culture that was identified in the interview process supported the quantitative findings that indicated school culture is moving in a positive direction and was positively impacted by the implementation of the Innovative Hybrid Schedule. When questioned during the interview process Teacher 7 stated:

It has helped certainly by being able to connect with colleagues on specific things, because we're so individualized as teachers that we're focused on our content area, so it's been actually very helpful, very beneficial, to discuss what works, what doesn't work, sharing information, and sharing strategies with other teachers... 
Walker, A. (2020). A Case Study on School Innovation and Change. Advances in Social Sciences Research Journal, 7(4) 148-163.

Teacher 9 shared:

I think it's created a positive school culture. I feel like teachers are competent in the area that they're teaching, especially the math teachers.

Teacher 6 supported the findings:

It has definitely had an overwhelming positive effect, we can definitely spend time focusing on becoming experts on our subject matter and not have to be so fragmented. I also think it's been positive in morale, which is kind of dealing with children, we're not stuck in the same room with the same behavior problems, the same children all day...

\section{Collaboration.}

Through the interview process, the researcher also discovered that a second emergent theme of collaboration among teachers promoted a positive change in school culture. Additionally, the effects of collaboration improved school and teacher morale because the organizational structure promotes professional learning communities in which the teachers share instructional practices. Teacher 1 who was an active participant in the implementation process at Stella Elementary School explained:

I think it's had a great effect on school morale and teachers, because we are encouraged to work together. We have to collaborate with each other for our students, and for our classrooms to be effective, and to run effectively.

Teacher 2 supported this finding:

I think the morale at the school is excellent since we started hybrid schedule, you have teachers that are able to be specialized in what they love teaching.

Teacher collaboration was a resounding point that Stella teachers found as facilitating factor and provided the key to successful implementation of the Innovative Hybrid Schedule. As Teacher 3 established:

I think what mostly helped the implementation process is the vertical planning where we all got together and we were able to look at our standards...

\section{Content Specialist}

Participants also reported that focusing on a few subjects and becoming a teacher content specialist was overwhelming key factor for implementing the Innovative Hybrid Schedule. The participants -Teacher 7 and Teacher 8 - expressed that they can focus deeply on the one or two subjects they teach and master the content and skills needed to teach their subject areas.

Teacher 8 stated:

We can provide individualized instruction in a content area, characteristic to a middle or high school setting, but more hands-on, small group, group work, time for peers to interact. Certainly for myself as the educator, a lot of room to really perfect the area that I'm instructing. Teachers are being better prepared.

Teacher 7 concurred:

Teaching specific content areas, I believe really allows a lot of confidence for the teachers, the instructors, for perfecting their curriculum and perfecting the standards and understanding exactly what their content area is. 
Regardless of the type of innovation, literature on leadership suggests the principals' understanding of organizational change and organizational learning as guides for effectively implementing the innovation. The literature identified that a key to successful implementation of an innovation or change is create a context that supports practices that foster professional learning within an organization. The interviews with Stella teachers described how the structure of the innovative hybrid schedule supported professional learning opportunities. It provided the structure and organization for increased collaboration such as participating in content specific professional learning activities and vertical planning teams. Teachers described the innovative hybrid schedule enabled teachers to engage in collaboration, problem-solve, and improve their instructional practices. This requires changing the behaviors of teachers within a school engage in, the assumptions, beliefs, and values that the teachers have will begin to change. These changes assisted in creating a context for making a cultural shift.

\section{CONCLUSION}

The researcher of this study was interested in determining if an innovative hybrid schedule would improve school culture and impact student learning outcomes. The researcher sought to investigate if teachers perceived the innovative hybrid schedule created a context for collaboration which supported cultivating their instructional practices that ultimately improved student learning outcomes. The researcher believes that student learning outcomes should be the most important element concerning teachers, administrators, and educational leaders. While improving student learning is the ultimate goal of schools, it is necessary to recognize there are many factors such as school culture, organizational structure, and leadership styles that effect the student learning outcomes. The researcher recognizes the role that positive school culture and teacher collaboration have on improving student learning. When teachers collaborate with other teachers and become a content specialist by focusing on one content area, then the students and staff benefit from the positive outcomes.

Results suggested that because teachers were able to implement an educational change through an innovation, the two variables of student learning outcomes and school culture improved at the same time. Findings from this study will greatly contribute to the existing literature pertaining to implementing educational innovation, as well as, add insight to the literature related to the influences that the five attributes of professional learning have on sustaining a culture of innovation to improve schools and learning for students. Moreover, school leaders, researchers and educational stakeholders can utilize the findings of this study to gain insight on how schools organized to create a context for change can cultivate a culture that inspires teaching and learning improvements to meet the needs of students.

While there is no causal link, it is obvious that the professional learning community and collaboration improved and student learning improved during the implementation of the innovative hybrid schedule. The study indicated that the relationships between implementing an innovative change such as the innovative hybrid schedule and applying the five attributes of professional learning had a positive impact on the teacher collaboration, school culture, and providing the opportunities for teachers to become content specialist. The researcher confirmed that implementing a positive change in school culture improved student-learning outcomes. Teachers believed that the innovative hybrid schedule was the connection that created a context for change. Additionally, it provided the context for collaborative opportunities for professional 
Walker, A. (2020). A Case Study on School Innovation and Change. Advances in Social Sciences Research Journal, 7(4) 148 -163.

learning and vertical planning which were perceived as positive outcomes of the change initiative. Lastly, the innovative hybrid schedule allowed teachers to focus on one content area and become content specialist which ultimately factored in to the improvement in student learning outcomes.

\section{References}

Andrews, D., \& Crowther, F. (2002). Parallel leadership: a clue to the contents of the black box of school reform. International Journal of Educational Management, 16(4), 152-159.

Bolman, L. G., \& Deal, T. E. (2010). Reframing the path to school leadership, a guide for teachers and principals. Newbury Park, CA: Corwin Press

Cuban, L. (1990). Reforming again, again, and again. Educational Researcher, 19, 3-13.

Darling-Hammond, L. (2004). Standards, accountability, and school reform. Teachers College Record, 106(6), 10471085.

Deal, T. E., \& Peterson, K. D. (1999). Shaping the school culture: The heart of leadership. San Francisco: Jossey-Bass.

Dropsey, M. (2004). Departmentalization in elementary schools (Master's thesis). Retrieved from http://personal.ashland.edu/dkommer/Inq\%20Papers\%20Fall\%2004/Dropsey\%20Final.pdf

DuFour, R., DuFour, R., Eaker, R., \& Many, T. (2006). Learning by doing. Bloomington, IN: Solution Tree.

DuFour, R. (2004, May). What is a "professional learning community"? Educational Leadership, 61(8), 6-11.

DuFour, R. (2007). Professional learning communities: A bandwagon, an idea worth considering, or our best hope for high levels of learning? Middle School Journal, 39(4), 1-8.

Dufour, DuFour, and Eaker. Revisiting professional learning communities at work: new insights for improving schools, Bloomington, IN: Solution Tree Press, 2008

Fullan, M. G. (1993). Why teachers must become change agents. Educational Leadership, 50, 12-12.

Fullan, M. (2007). The new meaning of educational change, 4th edition. New York: Teachers College Press.

Fullan, M., Hord, S. M., \& Frank, V. V. (2015). Reach the highest standard in professional learning: implementation. Thousand Oaks: Corwin.

Hall, G. E., \& Hord, S. M. (2015). Implementing change: patterns, principles, and potholes. Boston: Pearson.

Hall, G. E., \& Hord, S. M. (2011). Implementing change: patterns, principles, and potholes. Boston: Pearson.

Hinde, E. R. (2004). School culture and change: An examination of the effects of school culture on the process of change. Essays in Education, 11.

Hord, S. (2004). Professional learning communities: An overview. Learning Together, Leading Together: Changing Schools through Professional Learning Communities, 5-14.

Hord, S. M., \& Roussin, J. L. (2013). Implementing change through learning: Concerns-based concepts, tools, and strategies for guiding change. Thousand Oaks, CA: Corwin Press.

Hord, S. M., \& Sommers, W. A. (2008). Leading professional learning communities: Voices from research and practice. Thousand Oaks, CA: Corwin Press.

Huffman, J. B., \& Hipp, K. K. (2003). Reculturing schools as professional learning communities. Lanham, MD: Rowman \& Littlefield.

Kouzes, J. M., \& Posner, B. J. (2002). Leadership challenge (3rd ed.). San Francisco: Jossey-Bass.

Kruse, S., Seashore Louis, K., \& Bryk, A. (1994). Building professional community in schools. Issues in Restructuring Schools, Issue Report No. 6 (Spring 1994), 3-6.

Lewis, A. (1989). Restructuring America's schools. Arlington, VA: American Association of School Administrators. 
Louis, K. S., \& Kruse, S. D. (1995). Professionalism and community: perspectives on reforming urban schools. Thousand Oaks, CA: Corwin Press.

Miles, M. B., \& Huberman, A. M. (1984). Qualitative data analysis: a sourcebook of new methods. Beverly Hills: Sage Publications.

National Governors Association, Council of Chief State School Officers, and Achieve, Inc. (2008). Benchmarking for success: ensuring u.s. students receive a world class education. Washington, DC: Author.

National Governors Association Center for Best Practices \& Council of Chief State School Officers. (2012). Common core state standards initiative: preparing america's students for college and career. Retrieved from http://www.corestandards.org

Porter, A., McMaken, J., Hwang, J., \& Yang, R. (2011). Common core standards: The new U.S. intended curriculum. Educational Researcher, 40(3), 103-116. Doi: 103102/0013189X11405038

Ravitch, D. (2010). The death and life of the great American school system: How testing and choice are undermining education. New York: Basic Books.

Schein, E. H. (1990). Organizational culture. American Psychologist,45(2), 109-119. doi:10.1037//0003-

Sergiovanni, T. J. (1992). Why we should seek substitutes for leadership. Educational Leadership. 5.41 - 45.

Sowers, P. (1968). Let's team teach in our elementary school. NASEC Monograph Series, Spectrum. Retrieved from ERIC database. (ED030941

Stoll, L. (2009). Connecting learning communities: Capacity building for systemic change. In A. Hargreaves, A. Lieberman, M. Fullan, \& D. Hopkins (Eds.), Second International Handbook of Educational Change (pp. 469-484). Dordrecht, Netherlands: Springer International.

Tyack, D. B., \& Cuban, L. (1995). Tinkering toward utopia: A century of public school reform. Cambridge, MA: Harvard University Press.

Wehlage, A., \& Newman, F. (1993). The ten commandments of business and how to break them By Bill Fromm. Performance Instruction,32(5), 24-24. doi:10.1002/pfi.4170320511 